\title{
Building a microphysiological skin model from induced pluripotent stem cells
}

\author{
Zongyou Guo', Claire A Higgins', Brian M Gillette², Munenari Itoh', Noriko Umegaki', Karl Gledhill', Samuel K Sia² \\ and Angela M Christiano*1,3
}

\begin{abstract}
The discovery of induced pluripotent stem cells (iPSCs) in 2006 was a major breakthrough for regenerative medicine. The establishment of patient-specific iPSCS has created the opportunity to model diseases in culture systems, with the potential to rapidly advance the drug discovery field. Current methods of drug discovery are inefficient, with a high proportion of drug candidates failing during clinical trials due to low efficacy and/or high toxicity. Many drugs fail toxicity testing during clinical trials, since the cells on which they have been tested do not adequately model three-dimensional tissues or their interaction with other organs in the body. There is a need to develop microphysiological systems that reliably represent both an intact tissue and also the interaction of a particular tissue with other systems throughout the body. As the port of entry for many drugs is via topical delivery, the skin is the first line of exposure, and also one of the first organs to demonstrate a reaction after systemic drug delivery. In this review, we discuss our strategy to develop a microphysiological system using iPSCs that recapitulates human skin for analyzing the interactions of drugs with the skin.
\end{abstract}

\section{Background \\ A requirement for advancement of drug discovery methods}

Currently, drug candidates qualify for clinical trials after multiple rounds of screening using biochemical assays, cultured cells and several animal models. However, despite this rigorous assessment process, approximately

*Correspondence: amc65@columbia.edu

Columbia University, College of Physicians \& Surgeons, Russ Berrie Medical Science Pavilion, 1150 St. Nicholas Avenue, Room 303B, New York, NY 10032, USA

Full list of author information is available at the end of the article
$88 \%$ of drugs entering clinical trials fail, either due to low efficacy and/or high toxicity [1]. This high failure rate is often attributed to inadequate models that do not faithfully represent human tissues or recapitulate the interaction between organs. There is an urgent need to establish surrogate systems that more closely mimic human tissues and relevant physiological conditions.

The use of mice for drug testing prior to human clinical trials is a standard procedure. However, mouse and human skin have vastly different architecture, responsiveness and functionality, due to differences in thickness, hair density, and appendages [2]. Moreover, mouse skin (with the exception of footpads) is devoid of sweat glands [3]. The differences between mouse and human skin greatly compromise the utility of murine animals as an experimental model to study human skin.

Concomitant with using animal models, new drugs are also screened using human cell cultures. A large majority of cell culture screening methods rely on the use of cells cultured under two-dimensional conditions. However, growth in two-dimensional culture conditions can impose highly unnatural constraints on cells [4], and as a result many fields are beginning to adopt threedimensional (3D) cultures for drug testing, since they more reliably resemble in vivo structures, both morphologically and biochemically [5]. Under 3D culture conditions, fibroblasts are able to support keratinocytes to differentiate into a well-structured epidermis [6]. Indeed, $3 \mathrm{D}$ skin equivalents have been developed using normal human fibroblasts and keratinocytes, and are used in a broad range of applications including disease modeling and drug discovery [7].

\section{Current cultured skin models}

Driven by the need to treat burns and chronic wounds, the first human skin-like constructs were developed in the early 1980s [8]. There have been a few adaptations to this protocol, but the general principles that govern human skin equivalent development remain largely the same as 30 years ago, with skin constructs today being predominantly comprised of fibroblasts in a collagen matrix, overlaid with epidermal keratinocytes $[9,10]$. 
In recent years there has been significant interest in improving skin constructs, resulting in the development of pigmented [11], vascularized [12] and immunocompetent skin constructs [13]. Recently, an innervated skin model was also developed [14]. Nevertheless, most skin models, containing only one or two cell types and lack skin appendages, and therefore are insufficient to capture the complexity of human skin.

\section{Skin complexity in drug response}

In addition to fibroblasts and keratinocytes, the skin contains large numbers of hair follicles, immune cells, melanocytes, Merkel cell complexes, blood vessels and nerve fibers [15]. Diseases of the skin can indicate an increased risk for separate co-morbid disorders. Two examples of this are palmoplantar keratoderma and psoriasis, both of which are associated with an increased risk for cardiovascular disease [16,17].

Moreover, the skin interacts with other organs within the body. For example, a brain-skin neuroendocrine axis has been well described that links the nervous system and the skin [18]. This critical axis is believed to be responsible for drug-related responses such as morphineinduced itch, where a subset of spinal neurons is activated by morphine, resulting in debilitating itching of the skin [19].

Another dramatic and adverse drug effect observed within the skin causes toxic epidermal necrolysis [20], which is usually observed after treatment with anticonvulsive drugs. The factors that govern susceptibility to this secondary reaction are unknown. However, toxic epidermal necrolysis starts as a dermal inflammation that can progress to cover a large proportion of the body surface, resulting in epidermal detachment at the dermal-epidermal junction [21]. Toxic epidermal necrolysis is often accompanied by a toxic drug reaction in the liver [22], indicating the presence of a skin-liver axis. Evaluation of human skin equivalents alongside other organs is important to evaluate co-morbid toxic effects of new drugs or compounds.

\section{Advantages of induced pluripotent stem cells as cell sources for construction of three-dimensional skin models} To generate a complex skin model interacting with other human organs would require multiple cell types, which would be impossible to accomplish with somatic cells due to their limited availability, even though some cancer cell lines may have sufficient growth potential for 3D skin construction. The development of induced pluripotent stem cell (iPSC) technology enables us to obtain a large number of cells with unlimited growth potential from a limited number of somatic cells [23] and from noninvasive sources such as blood [24]. In addition, our recent construction of human skin equivalents entirely from iPSC-derived fibroblasts and keratinocytes [25] demonstrates the feasibility of construction of iPSCbased 3D skin models.

Generation and differentiation of iPSCs are timeconsuming and expensive procedures, but the unlimited growth potential of iPSCs allows investigators to share cell resources for different diseases, and to screen more drug candidates for interactions [26]. iPSCs have the capacity to differentiate into different cell types [27], which allows the establishment of multiorgan systems to model human physiological conditions, and perform toxicity studies [28]. In addition, a panel of iPSCs can be created from individuals with different genetic variations to represent the diverse human population [26]. Taken together, iPSC technology can allow us to mimic clinical trials in vitro to obtain efficacy and toxicity data that will reduce the drug attrition rate during patient-based clinical trials [26]. The improvement in iPSC generation and differentiation protocols will further enhance the cost-effectiveness of iPSCs for drug discovery.

iPSCs technology at the current time has noteworthy limitations, including retention of an epigenetic memory of their parental somatic cells [29], variability among iPSC lines [30] and genomic instability [31]. These limitations may impair the ability of iPSCs to model human diseases for drug development. However, several solutions may be implemented to overcome such limitations, including using small molecules to reduce the effect of the residual epigenetic state [32]. Generation of several iPSC lines from different donors can help to minimize variability [33], and avoiding direct targeting of p53 during reprogramming can serve to decrease iPSC genomic instability [34]. With a better understanding of the mechanisms underlying cell reprogramming, we anticipate that iPSCs will be produced and differentiated in a more controlled fashion in the future.

\section{Variability issues in three-dimensional skin constructs}

Construction of 3D skin equivalents is a complex procedure, involving biomaterials and different cell types. Because iPSCs vary among different lines [30] and iPSCdifferentiated cells are heterogeneous with different differentiation stages [26], inclusion of iPSC-derived cells may increase variability in $3 \mathrm{D}$ skin constructs. Several standards will need to be achieved to ensure the reliability of a 3D skin system for drug interactions with the skin. Variations in iPSC-derived cells such as fibroblasts and keratinocytes may be minimized by establishing a set of selection criteria, such as expression of cell-specific markers, assessment of proliferation rate and lifespan, and establishment of gene expression signatures. The quality of 3D skin constructs can be guaranteed by criteria such as histological analysis, cell viability tests and barrier function assays [35]. Moreover, intended skin 
disease model systems will need to reflect the corresponding disease state [36], such as the thickening of the epidermal layer in an in vitro psoriatic skin model [37]. In addition to standardization of protocols for 3D skin construction and cell reprogramming, strict quality control procedures will be required so that iPSC-based $3 \mathrm{D}$ skin models can be reliably incorporated into the drug development process.

\section{Knowledge gaps and future research directions Construction of skin equivalents using iPSC-derived keratinocytes and fibroblasts}

A complex in vitro skin model has a higher potential to mimic human skin than its simple two-layer counterparts, and thus can be more useful in efficacy and toxicity studies for drug discovery. To develop a complex skin equivalent, one strategy would be to construct a basic model (containing fibroblasts and keratinocytes) and then enhance the complexity by addition of more cell types. Due to the long-standing interest in 3D skin models, a variety of human skin equivalents have been developed using a range of natural or synthetic biomaterials [38], exogenous scaffolding biomaterials that are dispensable for 3D skin construction [39]. We aim to apply the most commonly used collagen scaffold, which would be beneficial for adapting the resultant skin models by different laboratories for validation.

The discovery of iPSCs has made it possible for a large number of cells to be obtained from a small number of somatic cells [23]. Moreover, use of patient-specific iPSCs allows enhanced study of a particular disease state [40]. We will establish skin constructs using collagen as a scaffold for iPSC-derived fibroblasts and keratinocytes (Figure 1), from both normal and diseased cells. We and others have developed protocols for establishment of both keratinocytes and fibroblasts from iPSCs, and have established human skin equivalents with one [41-43] or both [25] of these iPSC-derived cell types. Addition of more cell types to establish complex skin models from patient-specific iPSCs for drug testing would be especially beneficial for complex diseases such as psoriasis.

\section{Vascularization of skin equivalents using iPSC-derived endothelial cells}

One of our current research goals is to establish a skin construct in which we can mimic different modes of drug delivery (topical or systemic) [44] for studying drug interactions with the skin. While topical delivery can be easily replicated (since the epidermal surface of a skin construct is exposed to the air interface), mimicking systemic delivery requires the development of vascular channels within the dermal construct. We aim to establish vascular networks within the dermal portion of our skin constructs using a sacrificial hydrogel material to define open microvascular channels within the dermal scaffold. Gelatin, agarose, or alginate hydrogels can be used as sacrificial materials, which can be gelled and solubilized into a defined microvascular pattern, without affecting cell viability (for example, by heating or cooling in physiologic temperature ranges for gelatin and agarose, and by applying calcium or calcium chelators for alginate). Fibroblast-seeded collagen (which constitutes the dermal scaffold) is then cast around this sacrificial hydrogel channel network, which is then dissolved, resulting in a dermal scaffold containing an open microchannel network (Figure 2). An endothelial barrier is established by flowing in endothelial cells that attach to the open channel surfaces and form a monolayer [45]. Medium can be flowed through the channels to feed the constructs, enabling us to avoid the drastic fluctuation of $\mathrm{pH}$ and nutrients in the media, which would otherwise be encountered with traditional medium change practices. This microfabrication approach allows a complex, 3D tissue made of multiple cell types to be constructed. Importantly, the endothelial cells lining the channels can also be iPSC derived, following a recently published protocol [46].

\section{Construction of pigmented skin equivalent using iPSC-derived melanocytes}

Skin pigmentation is affected by many external and internal factors, such as ultraviolet, drugs, chemicals, inflammation and hormones, with keratinocytes in the skin acting to control skin pigmentation through the regulation of melanocytes and their melanin production [47]. Adverse responses to certain drugs, including pain relievers and some psychoactive medications, can manifest with hyperpigmentation of the skin [47]. Inclusion of melanocytes into skin constructs will therefore enable us to utilize variations in skin pigmentation as a readout for pharmaceutical screening of drugs that may cause sunlight-induced darkening of the skin.

Pigmented skin equivalents have been previously established by seeding melanocytes along with keratinocytes onto a dermal skin construct [48]. Melanocytes and keratinocytes are able to self-organize, resulting in the production of pigmented skin. However, in keeping with the theme of developing skin constructs using cells from a single individual for patient-specific drug targeting, we aim to establish human skin constructs containing iPSCderived melanocytes, which originate from the same donor of the fibroblasts, endothelial and epithelial cells within the construct. Progress within the stem cell field is rapid, and recently a protocol was published reporting the differentiation of iPSCs into melanocytes [49]. We will utilize this protocol to incorporate iPSC-derived melanocytes into our patient-specific skin equivalents. 


Reprogramming Differentiation
(fibroblasts)
Figure 1. Schematic diagram of generating induced pluripotent stem cells to create three-dimensional skin equivalents for drug testing.
Human somatic cells such as skin fibroblasts can be reprogrammed into induced pluripotent stem cells (iPSCs), from which various cell types
(including fibroblasts and keratinocytes) can be differentiated. Subsequently, the iPSC-derived cells can be combined with collagen to reconstitute
three-dimensional (3D) skin constructs for drug testing.

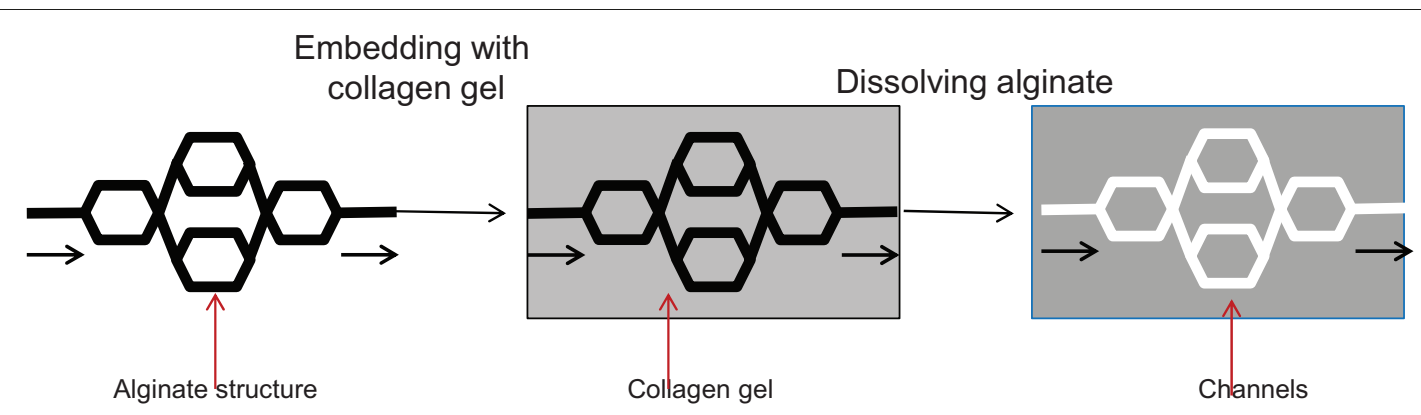

Figure 2. Schematic diagram of microfluidic channels fabricated with sacrificial alginate. A sacrificial alginate construct will be fabricated using a polydimethylsiloxane mold and embedded in a collagen gel. Subsequent removal of alginate will leave behind a void that can serve as channels.

Such constructs can then be exposed to UVB to mimic the environmental effect of sunlight.

\section{Integration of the skin microphysiological system with other organs}

Recently, there has been growing interest in human-ona-chip systems, in which different human organs such as the liver, heart and lung are connected in a microphysiological system [50]. By incorporating a vascular network into our skin equivalents, the equivalents can be directly plugged into a portal that is connected to the other organs through a microfluidic system (Figure 3), similar to a configuration described previously [51]. Questions now relate to the longevity of skin equivalents, which usually show deterioration within the dermal compartment of the equivalent approximately 2 weeks after culturing at the air-liquid interface, leaving only a small amount of time for postproduction manipulation including drug screening. This deterioration is usually due to degradation of collagen in the construct [52]. However, the life of human skin equivalents can be prolonged up to 15 weeks, using approaches such as reinforcing the scaffolds in the dermal compartment [53] and/or inclusion of protease inhibitors in the culture medium [54]. We will take measures to ensure that 3D skin constructs have sufficient lifespan for drug development studies. Additionally, the development of a universal medium that will flow through all systems and support growth of multiple organs is required.

The skin interacts with the peripheral sensory nervous system, the autonomic nervous system, and the central nervous system in the brain-skin neuroendocrine axis [18]. Activation of the cutaneous nervous system is also involved in various skin diseases such as psoriasis [55]. We are working to innervate our skin model so we are able to mimic the interactions between the skin and the brain, conferring an enhanced sensitivity for pharmaceutical screening. To this end, Schwann cells and peripheral neurons can be differentiated from iPSC-derived neural crest stem cells [56] and then integrated into 3D skin constructs $[14,57]$.

\section{Skin microphysiological system as a tool for studying drug interactions in the skin}

Human skin equivalents have been widely used in skin disease modeling [36] and pharmacological studies [58]. Different 3D skin disease models display different characteristics associated with corresponding diseases [36]. The alleviation of disease-related symptoms, such as decreased expression of cytokeratin 16, interleukin- 8 and tumor necrosis factor alpha in a psoriatic model [59], for example, may be an indication of drug efficacy. For hyperpigmentation-related drugs, melanin content can be quantified as described elsewhere [60]. Previous 


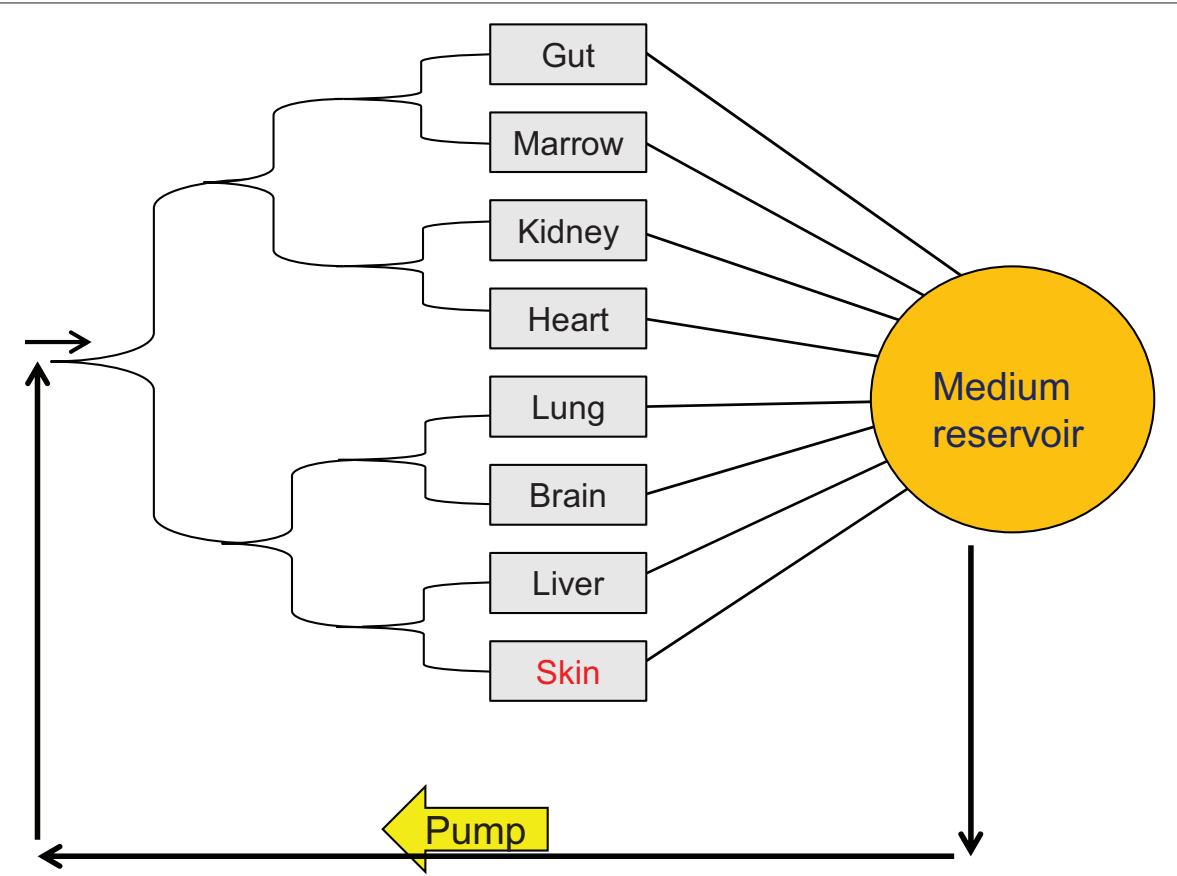

Figure 3. Schematic diagram of a multiorgan system. Different organs can be integrated as indicated. In this system, only a single pump will be needed to recirculate a common medium through different organs. Eight organs are shown in this system, but the configuration can be modified to accommodate different number of human organs.

studies with different compounds on in vitro 3D skin models have revealed several sensitive readouts, including disruption of structural integrity, loss of barrier function, reduced cell viability and elevated levels of interleukin- $1 \alpha$ in the medium [61]. Not surprisingly, release of interleukin- $1 \alpha$ from keratinocytes is a primary event in the skin defense mechanism in response to damage [62]. We aim to evaluate these parameters for toxicity assays. Establishment of reliable drug screening protocols using skin equivalents will generate valuable efficacy and toxicity data to aid in drug discovery and screening.

\section{Future directions}

Skin is a highly complex organ containing hair follicles, sweat glands, and nervous, lymphatic and vascular systems, among many other cell types within the dermis and epidermis. Current skin models are very basic, and only replicate the two main compartments of human skin, keratinocytes and fibroblasts. Our research plan is to gradually incorporate different cell types into our human skin equivalents, in order to better replicate a functional human skin. While we are starting by introducing pigmentation and blood vessels, our longterm goals are to establish a highly complex skin construct that includes hair follicles, nerves, and immune cells to reliably mimic human skin.
We will aim to generate hair follicles in skin constructs using iPSC-derived papilla cells. Dermal papilla cells are specialized fibroblasts located at the base of the hair follicle and are crucial for hair follicle development. Cultured dermal papilla cells have previously been used to instruct hair growth in recipient tissues using both rodent and human cells $[63,64]$. However, to date, dermal papilla cells have not been successfully differentiated from iPSCs. Development of a robust procedure to differentiate iPSC-derived papilla cells from iPSCs will provide us with an unprecedented opportunity to utilize iPSCs for regenerative medicine.

To generate skin constructs containing immune components, precursors of dendritic cells can be incorporated into constructs, to then be differentiated into Langerhans cells in the epidermis and into dendritic cells in the dermis [13]. T cells can be derived from iPSCs with a published protocol [65], and procedures to co-culture $\mathrm{T}$ cells with keratinocytes [66] or fibroblasts [67] can be adapted to integrate iPSC-derived T cells into a complex 3D skin system.

In closing, incorporation of different iPSC-derived cell types into vascularized human skin equivalents will enable us to replicate complex skin disorders in vitro. Launching human-on-a-chip systems will enable us to better mimic human physiological conditions and to more efficiently assess the efficacy and toxicity of drug candidates to treat human disease. 


\section{Abbreviations}

3D, three-dimensional; iPSC, induced pluripotent stem cell.

\section{Competing interests}

The authors declare that they have no competing interests.

\section{Acknowledgements}

The authors are grateful for technical support from Ming Zhang. This work was supported by a Skin Disease Research Center grant from the NIH/NIAMS (P30AR044535), a Mandl Connective Tissue Research fellowship, a Helmsley Foundation grant starter from the Columbia Stem Cell Initiative, NYSTAR and NYSTEM, and lastly by the NIH/NCATS Microphysiological Systems Program (U18TR000561). The funding for the publication costs associated with this article comes from NIH grant 5U18TR000561-02.

\section{Declarations}

Publication of this supplement has not been supported by sponsorship. Articles have undergone the journal's standard review process. The Editors declare that they have no competing interests.

This article has been published as part of Stem Cell Research \& Therapy Volume 4 Supplement 1, 2013: Stem cells on bioengineered microphysiological platforms for disease modeling and drug testing. The full contents of the supplement are available online at http://www.stemcellres.com/supplements/4/S1.

\section{Author details}

'Department of Dermatology, Columbia University, College of Physicians \& Surgeons, Russ Berrie Medical Science Pavilion, 1150 St. Nicholas Avenue, Room 303B, New York, NY 10032, USA. ${ }^{2}$ Department of Biomedical Engineering, Columbia University, 351 Engineering Terrace, 1210 Amsterdam Avenue, New York, NY 10027, USA. ${ }^{3}$ Department of Genetics and Development, Columbia University, College of Physicians \& Surgeons, Russ Berrie Medical Science Pavilion, 1150 St. Nicholas Avenue, Room 303B, New York, NY 10032, USA

\section{Published: 20 December 2013}

\section{References}

1. Paul SM, Mytelka DS, Dunwiddie CT, Persinger CC, Munos BH, Lindborg SR, Schacht AL: How to improve R\&D productivity: the pharmaceutical industry's grand challenge. Nat Rev Drug Discov 2010, 9:203-214.

2. Brohem CA, Cardeal LB, Tiago M, Soengas MS, Barros SB, Maria-Engler SS: Artificial skin in perspective: concepts and applications. Pigment Cell Melanoma Res 2011, 24:35-50.

3. Taylor DK, Bubier JA, Silva KA, Sundberg JP: Development, structure, and keratin expression in C57BL/6J mouse eccrine glands. Vet Pathol 2012, 49:146-154

4. Birgersdotter A, Sandberg R, Ernberg I: Gene expression perturbation in vitro - a growing case for three-dimensional (3D) culture systems. Semin Cancer Biol 2005, 15:405-412.

5. Tung YC, Hsiao AY, Allen SG, Torisawa YS, Ho M, Takayama S: High-throughput 3D spheroid culture and drug testing using a 384 hanging drop array. Analyst 2011, 136:473-478

6. Stark HJ, Szabowski A, Fusenig NE, Maas-Szabowski N: Organotypic cocultures as skin equivalents: a complex and sophisticated in vitro system. Biol Proced Online 2004, 6:55-60.

7. Groeber F, Holeiter M, Hampel M, Hinderer S, Schenke-Layland K: Skin tissue engineering - in vivo and in vitro applications. Adv Drug Deliv Rev 2011, 63:352-366.

8. Bell E, Ehrlich HP, Buttle DJ, Nakatsuji T: Living tissue formed in vitro and accepted as skin-equivalent tissue of full thickness. Science 1981, 211:1052-1054

9. Carlson MW, Alt-Holland A, Egles C, Garlick JA: Three-dimensional tissue models of normal and diseased skin. Curr Protoc Cell Biol 2008, Chapter 19:Unit 199

10. Gangatirkar P, Paquet-Fifield S, Li A, Rossi R, Kaur P: Establishment of 3D organotypic cultures using human neonatal epidermal cells. Nat Protoc 2007, 2:178-186

11. Topol BM, Haimes HB, Dubertret L, Bell E: Transfer of melanosomes in a skin equivalent model in vitro. J Invest Dermatol 1986, 87:642-647.
12. Hudon V, Berthod F, Black AF, Damour O, Germain L, Auger FA: A tissueengineered endothelialized dermis to study the modulation of angiogenic and angiostatic molecules on capillary-like tube formation in vitro. Br J Dermatol 2003, 148:1094-1104.

13. Bechetoille N, Dezutter-Dambuyant C, Damour O, Andre V, Orly I, Perrier E: Effects of solar ultraviolet radiation on engineered human skin equivalent containing both Langerhans cells and dermal dendritic cells. Tissue Eng 2007, 13:2667-2679.

14. Roggenkamp D, Kopnick S, Stab F, Wenck H, Schmelz M, Neufang G Epidermal nerve fibers modulate keratinocyte growth via neuropeptide signaling in an innervated skin model. J Invest Dermato/ 2013, 133:1620-1628.

15. MacNeil S: Progress and opportunities for tissue-engineered skin. Nature 2007, 445:874-880

16. Hoeger PH, Yates RW, Harper Jl: Palmoplantar keratoderma associated with congenital heart disease. Br J Dermatol 1998, 138:506-509.

17. Boehncke WH: Perspective: don't be superficial. Nature 2012, 492:S55.

18. DeWeerdt S: Psychodermatology: an emotional response. Nature 2012, 492:S62-S63.

19. Liu XY, Liu ZC, Sun YG, Ross M, Kim S, Tsai FF, Li OF, Jeffry J, Kim JY, Loh HH, Chen ZF: Unidirectional cross-activation of GRPR by MOR1D uncouples itch and analgesia induced by opioids. Cell 2011, 147:447-458.

20. Redondo P, de Felipe I, de la Pena A, Aramendia JM, Vanaclocha V: Druginduced hypersensitivity syndrome and toxic epidermal necrolysis. Treatment with N-acetylcysteine. Br J Dermatol 1997, 136:645-646.

21. Gerull R, Nelle M, Schaible T: Toxic epidermal necrolysis and StevensJohnson syndrome: a review. Crit Care Med 2011, 39:1521-1532.

22. Roujeau JC, Stern RS: Severe adverse cutaneous reactions to drugs. NEngl J Med 1994, 331:1272-1285.

23. Takahashi K, Tanabe K, Ohnuki M, Narita M, Ichisaka T, Tomoda K, Yamanaka S: Induction of pluripotent stem cells from adult human fibroblasts by defined factors. Cell 2007, 131:861-872.

24. Loh YH, Agarwal S, Park IH, Urbach A, Huo H, Heffner GC, Kim K, Miller JD, Ng K, Daley GQ: Generation of induced pluripotent stem cells from human blood. Blood 2009, 113:5476-5479.

25. Itoh M, Umegaki-Arao N, Guo Z, Liu L, Higgins C, Christiano AM: Generation of $3 \mathrm{D}$ skin equivalents fully reconstituted from human induced pluripotent stem cells (iPSCs). PLOS ONE 2013, 8:e77673.

26. Grskovic M, Javaherian A, Strulovici B, Daley GQ: Induced pluripotent stem cells--opportunities for disease modelling and drug discovery. Nat Rev Drug Discov 2011, 10:915-929

27. Rowntree RK,McNeish JD: Induced pluripotent stem cells: opportunities as research and development tools in 21 st century drug discovery. Regen Med 2010, 5:557-568

28. van de Stolpe A,den Toonder J: Workshop meeting report Organs-onChips: human disease models. Lab Chip 2013, 13:3449-3470

29. Kim K, Zhao R, Doi A, Ng K, Unternaehrer J, Cahan P, Huo H, Loh YH, Aryee MJ, Lensch MW, Li H, Collins JJ, Feinberg AP, Daley GQ: Donor cell type can influence the epigenome and differentiation potential of human induced pluripotent stem cells. Nat Biotechnol 2011, 29:1117-1119.

30. Lister R, Pelizzola M, Kida YS, Hawkins RD, Nery JR, Hon G, Antosiewicz Bourget J, O'Malley R, Castanon R, Klugman S, Downes M, Yu R, Stewart R, Ren B, Thomson JA, Evans RM, Ecker JR: Hotspots of aberrant epigenomic reprogramming in human induced pluripotent stem cells. Nature 2011, 471:68-73.

31. Laurent LC, Ulitsky I, Slavin I, Tran H, Schork A, Morey R, Lynch C, Harness JV Lee S, Barrero MJ, Ku S, Martynova M, Semechkin R, Galat V, Gottesfeld J, Izpisua Belmonte JC, Murry C, Keirstead HS, Park HS, Schmidt U, Laslett AL, Muller FJ, Nievergelt CM, Shamir R, Loring JF: Dynamic changes in the copy number of pluripotency and cell proliferation genes in human ESCs and iPSCs during reprogramming and time in culture. Cell Stem Cell 2011, 8:106-118

32. Stadtfeld M, Apostolou E, Ferrari F, Choi J, Walsh RM, Chen T, Ooi SS, Kim SY, Bestor TH, Shioda T, Park PJ, Hochedlinger K: Ascorbic acid prevents loss of Dlk1-Dio3 imprinting and facilitates generation of all-iPS cell mice from terminally differentiated B cells. Nat Genet 2012, 44:398-405, S1-S2.

33. Vitale AM, Matigian NA, Ravishankar S, Bellette B, Wood SA, Wolvetang EJ, Mackay-Sim A: Variability in the generation of induced pluripotent stem cells: importance for disease modeling. Stem Cells Trans/ Med 2012, 1:641-650.

34. Lake BB, Fink J, Klemetsaune L, Fu X, Jeffers JR, Zambetti GP, Xu Y. 
Context-dependent enhancement of induced pluripotent stem cell reprogramming by silencing Puma. Stem Cells 2012, 30:888-897.

35. Tornier C, Amsellem C, Fraissinette Ade B, Alepee N: Assessment of the optimized SkinEthic Reconstructed Human Epidermis (RHE) 42 bis skin irritation protocol over 39 test substances. Toxicol In Vitro 2010, 24:245-256.

36. Semlin L, Schafer-Korting M, Borelli C, Korting HC: In vitro models for human skin disease. Drug Discov Today 2011, 16:132-139.

37. Jean J, Lapointe M, Soucy J, Pouliot R: Development of an in vitro psoriatic skin model by tissue engineering. J Dermatol Sci 2009, 53:19-25.

38. Auxenfans C, Fradette J, Lequeux C, Germain L, Kinikoglu B, Bechetoille N, Braye F, Auger FA, Damour O: Evolution of three dimensional skin equivalent models reconstructed in vitro by tissue engineering. Eur $\mathrm{J}$ Dermatol 2009, 19:107-113.

39. Michel M, L'Heureux N, Pouliot R, Xu W, Auger FA, Germain L: Characterization of a new tissue-engineered human skin equivalent with hair. In Vitro Cell Dev Biol Anim 1999, 35:318-326.

40. Maehr R, Chen S, Snitow M, Ludwig T, Yagasaki L, Goland R, Leibel RL, Melton DA: Generation of pluripotent stem cells from patients with type 1 diabetes. Proc Natl Acad Sci U S A 2009, 106:15768-15773.

41. Hewitt KJ, Shamis Y, Hayman RB, Margvelashvili M, Dong S, Carlson MW Garlick JA: Epigenetic and phenotypic profile of fibroblasts derived from induced pluripotent stem cells. PLOS One 2011, 6:e17128.

42. Itoh M, Kiuru M, Cairo MS, Christiano AM: Generation of keratinocytes from normal and recessive dystrophic epidermolysis bullosa-induced pluripotent stem cells. Proc Natl Acad Sci U S A 2011, 108:8797-8802.

43. Selekman JA, Grundl NJ, Kolz JM, Palecek SP: Efficient generation of functional epithelial and epidermal cells from human pluripotent stem cells under defined conditions. Tissue Eng Part C Methods 2013. [Epub ahead of print]

44. Tornier C, Rosdy M, Maibach HI: In vitro skin irritation testing on reconstituted human epidermis: reproducibility for 50 chemicals tested with two protocols. Toxicol In Vitro 2006, 20:401-416.

45. Golden AP,Tien J: Fabrication of microfluidic hydrogels using molded gelatin as a sacrificial element. Lab Chip 2007, 7:720-725.

46. Levenberg S, Ferreira LS, Chen-Konak L, KraehenbuehI TP, Langer R: Isolation, differentiation and characterization of vascular cells derived from human embryonic stem cells. Nat Protoc 2010, 5:1115-1126.

47. Costin GE, Hearing VJ: Human skin pigmentation: melanocytes modulate skin color in response to stress. FASEB J 2007, 21:976-994.

48. Li L, Fukunaga-Kalabis M, Herlyn M: The three-dimensional human skin reconstruct model: a tool to study normal skin and melanoma progression. J Vis Exp 2011, 54:e2937.

49. Ohta S, Imaizumi Y, Akamatsu W, Okano H, Kawakami Y: Generation of human melanocytes from induced pluripotent stem cells. Methods Mol Biol 2013, 989:193-215

50. Sung JH, Esch MB, Prot JM, Long CJ, Smith A, Hickman JJ, Shuler ML: Microfabricated mammalian organ systems and their integration into models of whole animals and humans. Lab Chip 2013, 13:1201-1212.

51. Huh D, Torisawa YS, Hamilton GA, Kim HJ, Ingber DE: Microengineered physiological biomimicry: organs-on-chips. Lab Chip 2012, 12:2156-2164.

52. Swope VB,Boyce ST: Differential expression of matrix metalloproteinase-1 in vitro corresponds to tissue morphogenesis and quality assurance of cultured skin substitutes. J Surg Res 2005, 128:79-86.
53. Stark HJ, Willhauck MJ, Mirancea N, Boehnke K, Nord I, Breitkreutz D, Pavesio A, Boukamp P, Fusenig NE: Authentic fibroblast matrix in dermal equivalents normalises epidermal histogenesis and dermoepidermal junction in organotypic co-culture. Eur J Cell Biol 2004, 83:631-645.

54. Muffler S, Stark HJ, Amoros M, Falkowska-Hansen B, Boehnke K, Buhring HJ Marme A, Bickenbach JR, Boukamp P: A stable niche supports long-term maintenance of human epidermal stem cells in organotypic cultures. Stem Cells 2008, 26:2506-2515.

55. Roosterman D, Goerge T, Schneider SW, Bunnett NW, Steinhoff M: Neuronal control of skin function: the skin as a neuroimmunoendocrine organ. Physiol Rev 2006, 86:1309-1379.

56. Wang A, Tang Z, Li X, Jiang Y, Tsou DA, Li S: Derivation of smooth muscle cells with neural crest origin from human induced pluripotent stem cells. Cells Tissues Organs 2012, 195:5-14.

57. Blais $\mathrm{M}, \mathrm{Grenier} \mathrm{M}$, Berthod F: Improvement of nerve regeneration in tissueengineered skin enriched with schwann cells. J Invest Dermato/ 2009, 129:2895-2900.

58. Robinson MK, Osborne R, Perkins MA: Strategies for the assessment of acute skin irritation potential. J Pharmacol Toxicol Methods 1999, 42:1-9.

59. Tjabringa G, Bergers M, van Rens D, de Boer R, Lamme E, Schalkwijk J: Development and validation of human psoriatic skin equivalents. Am J Pathol 2008, 173:815-823.

60. Friedmann PS,Gilchrest BA: Ultraviolet radiation directly induces pigment production by cultured human melanocytes. J Cell Physio/ 1987, 133:88-94.

61. Gibbs S: In vitro irritation models and immune reactions. Skin Pharmacol Physiol 2009, 22:103-113.

62. Nickoloff BJ, Griffiths CE, Barker JN: The role of adhesion molecules, chemotactic factors, and cytokines in inflammatory and neoplastic skin disease - 1990 update. J Invest Dermatol 1990, 94:151S-157S.

63. Higgins CA, Chen JC, Cerise JC, Jahoda CA, Christiano AM: Microenvironmental reprogramming by three-dimensional culture enables dermal papilla cells to induce de novo human hair follicle growth. Proc Natl Acad Sci U S A 2013, 110:19679-19688.

64. Jahoda CA, Horne KA, Oliver RF: Induction of hair growth by implantation of cultured dermal papilla cells. Nature 1984, 311:560-562.

65. Themeli M, Kloss CC, Ciriello G, Fedorov VD, Perna F, Gonen M, Sadelain M: Generation of tumor-targeted human T lymphocytes from induced pluripotent stem cells for cancer therapy. Nat Biotechnol 2013, 31:928-933.

66. Clark RA, Yamanaka K, Bai M, Dowgiert R, Kupper TS: Human skin cells support thymus-independent T cell development. J Clin Invest 2005, 115:3239-3249.

67. Pinto S, Schmidt K, Egle S, Stark HJ, Boukamp P, Kyewski B: An organotypic coculture model supporting proliferation and differentiation of medullary thymic epithelial cells and promiscuous gene expression. J Immuno/ 2013, 190:1085-1093.

doi:10.1186/scrt363

Cite this article as: Guo Z, et al.: Building a microphysiological skin model from induced pluripotent stem cells. Stem Cell Research \& Therapy 2013, 4(Suppl 1):S2. 